\title{
Challenging the Menstruation Taboo One Sale at a Time: The Role of Social Entrepreneurs in the Period Revolution
}

\author{
Maria Carmen Punzi and Mirjam Werner
}

\begin{abstract}
INTRODUCTION
What does entrepreneurship have to do with the menstruation taboo? What is the connection between innovation in menstrual products and advancement in gender equality? In the last few years, there has been a noticeable increase in attention toward menstruation (Radnor 2017). In 2015 alone, menstruation surpassed 167 mentions in the top five national news outlets, tripling from the numbers in the 2011 to 2014 period (Weiss-Wolf 2019). Actors spanning multiple roles and industries have stepped up to change how society talks about and relates to menstruation. As menstruation gains traction as a social issue, a number of astonishing problems are gaining increased visibility: lack of access to basic products to manage menstruation, especially—but not only - in the Global South (House, Mahon, and Cavill 2013); practices and traditions that threaten women's security and social inclusion during menstruating days (McMahon et al. 2011); and lack of transparency in the menstrual products industry (Kounang 2015), which has no specific requirements to disclose the ingredients in their products (Rabin 2017).

As controversial cultural and market practices continue to be exposed, the picture is becoming crystal clear: menstruation needs to be looked at in its complexity and has the potential to reveal new dimensions of discourses of gender equality (Schechtman 2015), good health (Sommer et al. 2015), access to education, and human rights (Thomas 2007; Human Rights Watch 2017). Unfortunately, milestone documents on global gender equality, like the European Commission 2016-2020 Strategic Engagement for Gender Equality (2015), the Sustainable Development Goals (2015), and the Global
\end{abstract}


Strategy for Women's, Children's and Adolescents' Health 2016-2030 (2015), represent missed opportunities to recognize how the menstruation taboo hinders gender equality, sustainable consumption, and a healthy life for all.

While institutions seem not to have grasped the urgency of the grand challenge of menstruation, activists throughout the globe have started using their platforms and voices to denounce the taboo that connects women confined to menstrual huts in Nepal (Bowman 2018); young girls skipping school days in the UK (Marsh 2017; Brooks 2018; George 2017); women's feelings of shame about their bodies; and under-regulation of the Femcare industry. Street marches and protests against the "tampon tax" started taking place, with campaigners calling for free menstrual products for girls in need, in the workplace, and in schools (Radnor 2017). Menstrual activism seems to offer a new angle to those fighting for gender equality, one that is inclusive and connects to common struggles. As pointed out by the Newsweek article that crowned 2015 as "the year of period," people have started "talking about gender equality, feminism, and social change through women's periods" (Jones 2016).

Building on interviews with 35 social entrepreneurs, communication with current and former employees of mainstream menstrual product companies, and participant observation of menstrual activists, this chapter aims to analyze the role of social entrepreneurs in this so-called 'period revolution.' Exploring the market strategies and social media messaging of social enterprises, along with the ways other activists in the menstrual equity movement question or support their work, this study analyzes the opportunities and potential pitfalls presented by social enterprises' involvement in the movement.

\section{Social Enterprises and the Market for Menstrual Products}

Given that menstrual experiences are mediated by their use, it is crucial to critically look at the market for menstrual products-expected to be worth $\$ 42.7$ billion by 2022 (Allied Market Research 2016). As Bobel (2010) points out, researchers and practitioners have not inquired into the real reasons why women hate their period more than other bodily processes and what role consumerism plays in that hate. For nearly a century, brands have reinforced narratives of secrecy and embarrassment, promising solutions that would save women from revealing to anyone that they were menstruating (Kissling 1996; Jackson and Falmagne 2013). Advertisements created needs and insecurities in consumers, in order to then suggest the purchase of a certain product which would solve them (Park 1996; Karzai 2010). The message was clear: the best sanitary product is the one that keeps women safe, doesn't leak, and hides their "condition" from the outer world (Newman 2010; Malefyt and McCabe 2016; Vostral 2008). Given that menstrual experiences are profoundly affected by how women choose to manage their cycle, the brands selling menstrual products have a powerful role in shaping 
the way society feels about periods. It is important, therefore, to look at the players that are creating and marketing the products millions of women and girls use every day to manage their period.

Currently, $80 \%$ of the Femcare industry is dominated by four main brands: Procter \& Gamble (introduced Always in 1983); Johnson \& Johnson/ Edgewell (developed o.b. in 1950); SCA (introduced Libresse in the 1940s); and Kimberly Clark (launched Kotex in 1920). While disposable pads and tampons have been the biggest players in the market for a long time, they haven't been the only ones. Brands selling sustainable options like menstrual cups and washable pads have been around since long before the 2015 wave of the period revolution and before they were tied to concepts like "social enterprises" and "B-corps." Before the turn of the twenty-first century, however, reusable products' brands tended to emphasize the environmental benefits of their product rather than their social impact, mainly because menstrual equity was not seen as an issue affecting the Global North. The companies that did sell cups and reusable pads-mainly in health food stores-were not positioning themselves as direct competitors or alternatives to the most established brands. Nor did they seek to spread awareness about "period poverty," a recently coined term (Weiss-Wolf 2019) that recasts menstruation as a rights-based issue (Bobel 2019).

Interviews with representatives of the reusable brands that have been on the market the longest reveal that their original target groups were mostly 'eco-consumers.' An interviewee from DivaCup-in business since 2002-reported:

When we had first started marketing the [cup] there was a lot of resistance from mainstream channels because it was a niche product at the time. [...] We worked through natural product channels, so a lot of health food stores and online retailers whose values lined up with what our product could offer.

A co-founder of one of the best-known menstrual cups reflected:

A menstrual cup is for everyone, not just for some health freaks or chemist freak - that's the reputation the menstrual cup had especially back in 2012-13. Most women thought it was only for these people who go to organic shops and never eat anything that is not $100 \%$ organic. Hippies kind of product.

An interviewee from GladRags, another long-standing reusable brand in the field, testifies:

We were founded in 1993 and in the beginning [...] we were marketed mostly to the very eco-friendly people who were really concerned about environmentalism. Now I think we've definitely shifted away from talking just about environmental benefits [of reusable products] because that's a little more obvious to people. 
In the past few years, new companies have emerged, often selling similar products but with different motivations. These "social enterprises" are organizations whose entrepreneurial activity has an embedded social purpose (Austin, Stevenson, and Wei-Skillern 2006). Much has been written about the term "social entrepreneurship" and there is not a common definition that scholars agree on. This is partly due to its recent appearance in the academic literature and partly due to the difficulty of measuring and putting a strict label on what "social" means. While "social enterprise" has been the most popular label among scholars, similar concepts have been introduced. Hockerts (2006), for example, calls “social purpose business ventures" those for-profit businesses whose main purpose of existence is to create external social benefits; Dorado (2006) renames "social entrepreneurial ventures" those ventures that blend business principles and social goals in new and creative ways, while other scholars have referred to them as "double bottom line organizations" (Dees 1998).

The core idea is that if commercial businesses tend to focus on-or even create-new needs, social businesses aim to serve basic, enduring needs more effectively by means of innovative approaches. The social entrepreneur recognizes a social need, demand, or market failure before starting the enterprise, while a commercial one looks for a large or growing total market (Austin, Stevenson, and Wei-Skillern 2006). These hybrid organizations often recognize and pursue opportunities to serve the social mission (Dees 1998), using a "business-like" and innovative approach to fulfill it. The emerging social innovation is seen as a business opportunity and turned into a commercial for-profit aimed at generating both social and economic value, a process that Emerson calls 'blended value' creation (2003).

In the last five or six years, organizations in the menstrual health space have started experimenting with this model (Ratcliff 2017), "using the power of business to fight for gender equality and provide products, education and jobs," as stated on the website of CORA, one of the best-known social enterprises in the space. They sell innovative products with the aim of changing the conversation about the menstrual cycle (Douglas 2017). By offering organic cotton pads and tampons or reusable options, these enterprises strive to change the Femcare industry-so far, loosely regulated and dominated by few disposable brands-and improve women's experience of menstruation.

The social enterprises working in and with the Global South mostly offer reusable options like menstrual cups or washable pads because they are inexpensive, long-term solutions (for example, RubyCup, EcoFemme, AfriPads). They can sell them at competitive prices thanks to subsidies and profits from sales in the Global North. The social enterprises don't stop at product distribution: they organize educational sessions and workshops that often feature local facilitators, creating safe spaces for users to learn about the menstrual cycle alongside the new product. Some of these initiatives also involve local women in the production process, building livelihoods 
and creating jobs. The objective is to help women and girls overcome the belief that their body is dirty while understanding that periods are normal and shouldn't exclude them from society (McMahon et al. 2011; Boosey and Wilson 2014). On the other hand, the businesses that focus their sales on the Global North countries strive to become lifestyle brands, making the menstrual experience comfortable through high-quality products (for example, FLEX, AuntFlow, DivaCup). By offering customized delivery services, customer support, and opportunities to ask questions online and return products, as well as ways to become part of a broader community, these social entrepreneurs have positioned their products as a means for women to take care of themselves.

Simultaneously, these enterprises are shedding light on something that the Global North has never considered its problem: "menstrual equity" (Weiss-Wolf 2019). Like the founder of the British social enterprise No More Taboo explains, people don't think of the Global North when thinking of menstruation as a social justice issue:

In the UK, [when asked about the menstruation taboo] people are like: "don't be silly, that just happens in Africa." Actually, when you start digging down and finding out, it's more subtle, [for example] people think you cannot swim on your period at all and all the things about menstrual blood being dirty, people still do believe that in the UK.

This attitude summed up how the lack of conversation and discussion about periods has resulted in the menstrual needs of homeless or underprivileged women being ignored in wealthier countries. A number of media outlets have recently called attention to how low-income families in the UK, especially those with more than one daughter, struggle to find the money for menstrual products (Marsh 2017; PLAN International UK 2018). In more than one case, data showed that girls miss school days and experience great embarrassment, discomfort, and isolation because they're unable to properly take care of their period.

Understanding the danger of dismissing menstrual equity as a "problem of the poor," some of the social enterprises make a conscious effort to overcome the wealth divide between beneficiaries and customers by inspiring a sense of empathy and connection among women worldwide. The language used on the companies' websites reflects this aim:

When you buy a Ruby Cup, you aren't just investing in a worry-free period for yourself, you're also sharing the same benefit with someone in need. (Ruby Cup 2020)

The cloth pad is good for your body, for the earth and connects you with others as your purchase gives dignified livelihood to rural women who stitch pads and enables access to product to poor girls. (EcoFemme, n.d.)

People helping people. Period. (Aunt Flow 2020) 
The social entrepreneurs are cautious of working on a clear-cut division of wealthy versus poor or of assuming, generalizing, and misunderstanding practices that need to be fully contextualized in order to be correctly addressed. Religious and cultural understandings of menstruation are different for each community and geographical location; they have changed in a number of places and are in the process of being reassessed in others. This means that working with menstrual products-wherever in the worldrequires sensitivity and a willingness to receive and integrate feedback from users, no matter their income or cultural beliefs.

\section{SKePTICISM AND CRITIQUeS}

The social enterprise model has been both contested and praised, in other fields as much as in menstrual health. Supporters highlight its potential benefits: empowering girls and women with education and access to more financially and environmentally sustainable solutions, as well as offering freedom from the short-term funding and bureaucracy nonprofit organizations often struggle with. Social entrepreneurship offers the agility of a startup, the ability to hear first-hand accounts from product users through social media and customer engagement, and the opportunity to combine product innovation with social impact and financial sustainability. Nonetheless, there is a certain degree of skepticism around the rapid growth of these hybrid organizations: Is there a need for social enterprises? Are they free-riders or are they genuinely contributing to the period revolution? Critics include activists, scholars, and mainstream Femcare brands.

Activists committed to the period revolution raise the question of how genuine the work of the social entrepreneurs is. Looking at the companies' efforts to make their social projects an appealing point of distinction from other brands, journalist Miller voices activists' concerns, asking: "how authentic is your mission if you're trying to sell stuff?" (2016). The fact that "giving back" can be used as a selling point for these brands raises some concerns. "Does it matter which business is most noble? Not really and there's something inherently icky about branding a natural biological process that actually has nothing to do with self-expression as a capital F feminist movement," continues Miller (2016).

Can a business genuinely take up an activist message like the one of the period revolution? How honest can participation in a social movement be when there is an economic exchange between the company and customers? Some activists remark that a number of brands claiming to be steering the period revolution are simply revisiting product concepts that have been on the market for decades. From their point of view, making organic cotton tampons and period underwear sound like the invention of the century is deceiving and unfair to those companies that started selling those products a long time ago. In the words of Jennifer Weiss-Wolf, "is branding menstruation - even if packaged in all the popular vernacular of feminism, 
autonomy and girl power - a genuine, viable form of activism?" (2019, 163). The lawyer and tampon tax expert stresses the hard balance between advancing a social agenda and running a successful company. Considering the agenda and messaging of the well-established menstrual product brands in the past decades, it is not surprising that activists worry about companies jumping on the menstrual equity bandwagon, using a social change message as a marketing strategy. Market mechanisms have been considered incompatible with a social agenda and the Femcare industry has done little to challenge that.

To differentiate themselves from mainstream pad and tampon brands, the social enterprises have depicted their own products as sustainable, transparent, and innovative alternatives. However, mainstream brands and activists alike raise doubts about the actual environmental and social impact of offering organic cotton products in the Western market or introducing reusable solutions in underprivileged communities in the Global South. From an ecological standpoint, the incumbents argue that it's still uncertain whether organic cotton is a more environmentally friendly option than traditional cotton. Cotton crops are generally subject to highly chemical processes that have an impact not only on the final products and therefore on consumers, but on farmers as well. Furthermore, while some organic cotton pads and tampons are marketed as biodegradable, for the decomposition process to take place they would need to be disposed of in a composting facility, which is often not possible. An R\&D expert working for one of the main traditional brands of pads and tampons explained:

\begin{abstract}
"I'm making an organic and biodegradable napkin," [they say] but there is no such thing. There are a lot of people claiming that, [but] if you understand the technology, they are not making a biodegradable napkin, they are making a napkin that might biodegrade if you put it in a composting facility. But since there are very few of them and since the product contains pathogens. It's never going to end there. (2019)
\end{abstract}

Despite the skepticism, the Femcare industry has started reacting to the momentum around sustainable, environmentally friendly products. In October 2018, Procter \& Gamble launched the first Tampax menstrual cup. A few months before that, they had acquired the startup This is L., a manufacturer of organic pads and tampons; the transaction was rumored to be worth around \$100 million (Magistretti 2019). In April 2019, Edgewell launched an organic cotton version of the best-seller o.b. tampons, available with or without a plant-based applicator. While this may not be a direct result of the work of social entrepreneurs, traditional brands are undeniably trying to adjust their messaging and product offers to a fast-changing market.

Additionally, critics point out a major weakness in the social enterprise model: scalability and access to the resources needed to expand beyond localized projects. A former employee of one of the leading multinationals 
said, "I think it's sweet that these social enterprises think they're the only ones trying to do something about it, when their budget is ridiculous compared to the one of multinationals, which means that so is their impact." An R\&D expert from another major brand commented that, in his view, it is only possible to tackle the hygiene or the waste issue when providing access to menstrual products in disadvantaged communities (personal communication 2017). Disposable solutions are safer in terms of hygiene, because they don't require proper washing and drying and can be either thrown away or burned once used. However, they represent a significant challenge in terms of trash, considering that in many developing countries there is little-if anywaste infrastructure available. Reusable products, however, come with the risk of girls not washing, drying, and storing them properly, potentially raising the risk of infections.

On the social side, both activists and scholars have expressed caution and concerns when assessing the impact of (only) distributing or selling products. Sinu Joseph, a local Indian activist working in menstrual health education, wrote on her website "Mythri Speaks":

When I started the Menstrual Hygiene awareness initiative 3 years ago [2010], I assumed the answer to menstrual hygiene was distributing Sanitary Napkins. So, we got donors and napkins and gave them for free in rural government schools. And then, we ran out of donors. And then, a small voice in my head asked me why I never bothered to ask the girls if they did need Sanitary Napkins and what they would do if I (or others like me) stopped supplying these. (Joseph 2013)

Scholar and expert Chris Bobel has also problematized the tendency to demonize the use of cloth or rags for menstrual management, which is sometimes described as an unhygienic and primitive practice, in order to justify the introduction of new products (2018).

When asked about the potential shortcomings of the solutions they offer, the social enterprises prove to be aware of them, but also convinced that they're doing their part in contributing to a positive shift in the industry. The social enterprises marketing organic disposables underline how they're changing the industry from the inside, offering a category of products for which there will always be demand:

No matter what product you're using, there is always going to be waste associated with it [. . . ]. Don't get me wrong, I love the idea of reusables. If we look at other things like cloth and nappies, I totally support that, but there is always going to be people who are going to be buying [tampons] and we are just trying to create the best product for that waste.

Organizations working in the Global South, on the other hand, claim to do their best in being mindful of the context they work in: 
We were skeptical and getting more and more uncomfortable with the growing number of organizations that were sort of jumping on this bandwagon of a horror scenario of girls in India, the need to fix it [...] which was probably well intentioned but a bit alarming because it's not contextualized. I think we have to be really careful when we come from another culture not to superimpose our own assumptions or projections of what's good or bad, sanitary or unsanitary.

\section{Contrasting Institutional Logics}

The concept of institutional logics can be helpful for understanding why social entrepreneurs face such skepticism when entering the menstrual health space. Institutional logics are defined as "taken-for-granted social prescriptions that represent shared understandings of what constitutes legitimate goals and how they may be pursued" (Battilana and Dorado 2010, 1420). While the menstrual activists and the big mainstream brands stand on opposite sides of the spectrum when it comes to approaching periods, they adhere to the same institutional logic: businesses are supposed to offer customers products, not engage in social change, and activists are supposed to advocate for political change, not promote products. This clear-cut division of tasks and responsibilities among societal stakeholders belongs to a traditional vision of the world that sees for-profit organizations and the market as sharply separated from the third sector and social impact. However, the institutional complexity that characterizes the twenty-first century world calls for collaborative and innovative responses. Hybrid organizations like social enterprises seem particularly adept at finding solutions as they are able to tap into a multiplicity of institutional elements, discourses, and tools in order to address these multifaceted issues in innovative ways (Battilana and Lee 2014; Tracey, Phillips, and Jarvis 2011). Combining competing institutional logics (Pache and Santos 2013), social enterprises apply business strategies to social change and vice versa.

The work and rationale of the social enterprises need to be understood and contextualized in relation to mainstream brands and not-for-profit organizations dedicated to women's health and sanitation. The social entrepreneurs in the menstrual health space see themselves as activists and social innovators while still caring for the success of their business operations. They are challenging the traditional way to do activism by maintaining that, while presenting the urgency of the issue is essential, it is potentially paralyzing if people are not offered means to act on it. By presenting a variety of innovative products, the social enterprises aim to empower women and men to take action in their daily lives and contribute to making change. While these are the objectives that the social entrepreneurs set out for themselves, for other stakeholders working in the space the question remains: does menstruation really need social entrepreneurship? Is there room among the propellers of the period revolution for such unconventional activists? To understand whether that's the case, it is worthwhile to look at what the approaches of stakeholders working in the realm of menstrual health have been so far. 
The branding and advertising of companies that have dominated the menstrual products space for decades have contributed to the secretive tones and the culture of shame surrounding menstruation (Kissling 1996; Vostral 2008; Freidenfelds 2009). It could be argued that this lack of conversation benefitted big companies by preventing competition and discouraging consumers from questioning the ingredients in the products or asking for more choices. In terms of their philanthropic efforts, the big players in the industry mainly engage in sporadic in-kind donations in developing countries. The issue with this kind of initiative is that they often do not take into account that free products discount the value of the items, harm local markets, and make communities dependent on products they won't be able to get access to in the long-run (Wydick, Katz, and Janet 2014). From a business point of view, in terms of product innovation and for-profit logics, social enterprises strive to offer improved options, challenging the rules and mechanisms of the Femcare industry. For them, innovating also means getting to know their target audience: who they are talking and selling to, how they experience menstruation, and how that can be improved. They acknowledge the importance of customer support, offering continuous help and integrating feedback. Further, they have been able to create a strong social media following and online communities where people share experiences, doubts, and tips.

When it comes to the work of non-governmental organizations (NGOs), most programs targeting girls and women of reproductive age fall into either the Water Sanitation and Hygiene (WASH) or the Sexual and Reproductive Health and Rights (SRHR) areas. Menstrual health, located at the intersection of the two, has been mainly tackled as a collateral effect of other programs and not as an area to be addressed independently. Menstrual Hygiene Day, for example, was instituted by the German NGO WASH United, heavily focused on water and sanitation programs. Other long-standing NGOs working in family planning and sexual and reproductive health have mainly looked at menstruation through the lens of contraceptive methods and reproductive disorders. Essentially, the nonprofit world has not focused on menstrual health until recently, and even when it did, it has limited its programming to the Global South, due to donor requirements and budget availability. This represents a missed opportunity to help people in the Global North recognize that the menstruation taboo is part of their reality and beliefs too. Given that nonprofit organizations receive funding through individual and corporate donations, government support, and grants, some of their biggest struggles include short-term project design, bureaucratic processes, and dependence on short-term funding (Goggins Gregory and Howard 2009). One of the cornerstones of the social entrepreneurs' mission is to modernize those traditional philanthropic procedures; their model goes beyond simple product distribution, favoring long-lasting and holistic solutions that are supported by education, conversations, and engagement with local communities. While their holistic approach aims to improve livelihoods 
by involving women in the production of the products, engaging men and communities, and introducing the importance of body literacy, in practice this is not always successful.

\section{Reframing Menstruation: From Social Media TO Body Positivity}

While menstruation has gained considerable attention on global media outlets and social networks in the last couple of years, the topic still remains entrenched in discomfort and silence in most places in the world. A survey conducted by PLAN International UK in July 2017 with 1000 UK girls and young women revealed that $48 \%$ of them felt embarrassed by their period, with the figure rising to 56\% among 14-year-olds (PLAN International UK 2018). A survey of 1500 U.S. women commissioned by period-proof underwear brand THINX revealed that nearly $60 \%$ of women feel embarrassed when they menstruate (Siebert 2018). In the same sample, $71 \%$ of the women declared that they had hidden a pad or tampon from view on their way to the bathroom. Based on statistics like these from recent surveys and their own understanding of an opportunity for social change, the social entrepreneurs seek to start conversations, partnerships, and collaborations with nonprofit organizations, politicians, and artists working on all aspects of menstrual, reproductive, and women's health. Their mission is to change the narrative around menstruation by means of an innovative product that is likely to catch the eye of the consumer and spark a conversation.

What tools and strategies do social entrepreneurs use in their quest to change the way society perceives, talks about, and relates to menstruation? Firstly, social entrepreneurs use empowering language, shifting from the notion of female hygiene to menstrual health:

We started using more language like "caring for your cycle" and self-care. [Other brands use the term] feminine hygiene care but we really felt that speaking more about care for the body and the whole self, that would give women this understanding that ' $\mathrm{Oh}$, rather than this being a disgusting experience, I can see this as being caring for my body.'

Their messaging is meant to inspire body positivity and encourage women to become knowledgeable about their menstrual cycle and overall health. Examples of this can be found in their social media profiles or websites, which feature statements like:

We believe that periods are precious, that sweat is therapy, and that feeling $100 \%$ protected during both is the stuff of dreams. We're down with our discharge, even prouder of our pregnancy shows, runaway bladders are welcome here too. (Modibodi 2020) 
We believe it's time that all women lived totally, unapologetically free. Free from judgement. Free from self-doubt. And free to be yourself. That's why every intimates product that we design (and redesign and redesign) is made with one goal in mind: to make you feel more comfortable in your own skin. (Knix, n.d.)

They consciously drop the term hygiene, using health to convey a holistic sense of well-being beyond just cleanliness. While hygiene can be considered a personal matter, often tied to a responsibility for the woman to be attractive and socially accepted, health is a global concern. The social entrepreneurs want to bring awareness to menstruation as a social issue, not just a female problem.

Secondly, social entrepreneurs aim to inspire empathy and build global connections through the purchase of menstrual products. While a working woman living in a European city with a good salary and social security does not face the same menstrual challenges as a girl in rural East Africa, buying a menstrual cup or a pair of period underwear can make the former aware of the challenge that the latter faces monthly. This way, menstruation can be profoundly felt as a shared human experience. The founder of CORA, a U.S.-based organic cotton tampons and pads subscription, reflects on this:

[You're] giving women that perspective and helping them to have empathy for another woman who is going through this same experience but maybe having [. . .] much more negative consequences. [These women start seeing their period] as an opportunity to give back and to help another girl and actually perceive it as a force for good.

The chance of connecting does not end with the purchase: the social entrepreneurs have created online communities (for example, Blood Milk; THINX Periodical) and safe spaces where women share their stories of heavy and painful periods, doubts about health, and accounts of years being unsatisfied with the menstrual products available. Women have responded by connecting, getting personal, and stepping up in online and offline platform to share their experiences. These communities offer taboo-free spaces to find answers and access educational resources.

Thirdly, social entrepreneurs have invested in comfortable and high-quality products to encourage consumers to choose reusable or organic options over the inexpensive and practical ones that have always seemed to work fine. These include subscription boxes, reusable options that last up to a couple of years, and lux-feel products with stylish packaging. "I get a lot of customers commenting to me and taking pictures of the products on their shelves saying 'I am proud to have them on display now' whereas in the past they would have been tucked in the back cupboard or in the drawer," recalls the founder of Tsuno. The social entrepreneurs have steered away from the environmental argument predominantly used by reusable brands in the past and describe their menstrual products as comfortable, cost-effective, and easy 
to use, with less focus on eco-friendliness. The founder of easy., a subscription box that delivers organic cotton tampons to your door, has decided to include pampering products in the box:

I think people are loving that, the fact that our packaging comes with a fair trade chocolate bar and a little quote, I think it does make it into something that when you see your [tampon subscription] box you're excited, which is a total spin on what you usually feel when you get your period, "augh, here it is, again." So it's a way to make it into somewhat of a positive experience.

Finally, the social entrepreneurs have started speaking of themselves as innovators. Slogans like "We believe Lunette is the future of period care" (Lunette, n.d.), "Welcome to the New Period" (OrganiCup, n.d.), or "The future of menstrual care. To a better period" (LENA 2020) show how these brands are positioning themselves as disruptors and modernizers. From one generation to another, girls learn how to manage their period and keep it a discreet, personal matter. More often than not, they start their menstrual cycle journey by adopting the same product or brand their mother or elder female figure uses. This fact, combined with the secrecy that characterizes the menstrual discourse, results in little if any demand for innovation in product quality, performance, and brand attractiveness. To contrast this trend, social entrepreneurs consciously emphasize the importance of continuously improving menstrual product choices and performance for women all over the world. They see a link between stigmatization of menstruation and a lack of innovation in products. Because menstruation often comes with physical and psychological discomfort, women internalize the idea that they are destined to have a painful experience for the rest of their fertile years. This is reinforced by the negative language surrounding menstruation, resulting in a lack of effort toward improving menstrual experiences.

By stressing innovation, the social entrepreneurs demonstrate that menstruation is worth an investment of time, technology, and money. The co-founder of YONI, a Dutch social enterprise selling organic cotton pads, tampons, and panty liners, notes:

I don't think anything very inspirational happens in terms of what most tampons and pads packaging looks like [...] and so we felt like there was a very big opportunity to start approaching the subject and the product itself in a different way, that's been part of our company from the start.

While not all of these enterprises are offering a radically new product, they show a willingness to modernize the industry: they invest in marketing strategies, provocative messaging, and revolutionary packaging, while working on optimizing the quality of the product and the brand positioning. They embrace the for-profit model, making the case that financial sustainability can be a strong enabler for social innovation. 


\section{Conclusion}

This chapter has looked at social enterprises in the menstrual health space, analyzing their characteristics and how they are changing discourses of menstruation, and comparing them to other menstrual activists, philanthropic organizations, and mainstream Femcare brands. There is growing evidence that social entrepreneurs are affecting the organizations already working in this space. In the last year, some of the most established menstrual product brands have started advertising their philanthropic efforts and launching campaigns to inspire confidence in young girls or address 'period poverty': Always-Procter \& Gamble's brand-has committed to \#EndPeriodPoverty in the UK and North America by donating menstrual products to girls and women in need (Always, n.d.-a, -b). In 2017, for the first time in the history of traditional brands' advertisements, BodyForm debuted an ad featuring red liquid to represent menstrual blood, instead of the ever-present blue period (BodyForm 2017). Moreover, most tampons and pads brands have added a section to their websites that addresses concerns about Toxic Shock Syndrome (TSS) and ingredients in their products, even though tampon boxes in the United States have had TSS info since the 1980s, suggesting that consumers increasingly search for this kind of information online. Even though information and explanations stay quite vague, this change can be interpreted as a sign of increased customer awareness and demand for transparency. The most surprising change is surely the launch of the Tampax menstrual cup (Procter \& Gamble), on the market since October 2018. Simultaneously, non-governmental and nonprofit organizations are gravitating toward menstrual health, often looking into setting up social enterprise-like models in the countries they work in, like in the case of Simavi and Days for Girls.

Selling menstrual products helps social entrepreneurs address the societal discomfort around menstruation, uncovering the lack of understanding of women's bodies and fertility as well as society's fear of female imperfection (that is, being "leaky" or "dirty"). Instead of condemning practices, habits, and beliefs from other cultures, social enterprises make use of open dialogue and context sensitivity to establish a connection with women both in the Global South and Global North countries, ditching hierarchical and ideological models in favor of user-centered and innovative products. Where educational policies initiated by governments seem to slowly be adapting to current debates, social enterprises have an incomparable agility to communicate with consumers and improve their knowledge of menstrual issues through product experience and shame-free conversations on user-friendly platforms.

The contribution of the social enterprises to the period revolution may challenge the idea that the market and its mechanisms can only do harm. While advertisements and packaging were once thought of as the way for companies to create unnecessary needs and insecurities in consumers that could only be solved by purchasing their product, social entrepreneurs now 
use them to convey positive and educational messages. The question remains about what is going to happen to these social enterprises in the long run, considering the fast pace they are growing at. Will they reach untapped markets? Will they keep innovating products indefinitely? Will they outgrow the mainstream brands or be acquired by them? Could their social mission eventually be outweighed by business concerns? One thing is for sure: the period revolution is on, and the social entrepreneurs aspire to take the driver seat.

\section{REFERENCES}

Allied Market Research. 2016. "Feminine Hygiene Products Market by Type and Distribution Channel-Global Opportunity Analysis and Industry Forecast, 20152022." https://www.alliedmarketresearch.com/feminine-hygiene-market.

Always. n.d.-a. "ALWAYS Commits to \#EndPeriodPoverty in the UK." Accessed April 29, 2020. https://www.always.co.uk/en-gb/about-us/endperiodpoverty.

Always. n.d.-b. "Join Always to End Period Poverty!" Accessed April 29, 2020. https://always.com/en-us/about-us/end-period-poverty.

Aunt Flow. 2020. "Our Mission." Accessed April 29, 2020. https://www.goauntflow. com/pages/our-mission.

Austin, James, Howard Stevenson, and Jane Wei-Skillern. 2006. "Social and Commercial Entrepreneurship: Same, Different, or Both?" Entrepreneurship Theory and Practice 30, no. 1 (January): 1-22. https://doi.org/10.1111/j.1540-6520.2006.00107.x.

Battilana, Julie, and Matthew Lee. 2014. "Advancing Research on Hybrid OrganizingInsights from the Study of Social Enterprises." Academy of Management Annals 8 (1): 397-441. https://doi.org/10.5465/19416520.2014.893615.

Battilana, Julie, and Silvia Dorado. 2010. "Building Sustainable Hybrid Organizations: The Case of Commercial Microfinance Organizations." The Academy of Management Journal 53 (6): 1419-40. http://www.jstor.org/stable/ 29780265.

Bobel, Chris. 2010. New Blood: Third-Wave Feminism and the Politics of Menstruation. New Brunswick: Rutgers University Press.

Bobel, Chris. 2019. The Managed Body: Developing Girls and Menstrual Health in the Global South. Boston, MA: Palgrave Macmillan.

BodyForm. 2017. "Blood Normal." Video, 0:20. Posted [October 2017]. https:// www.youtube.com/watch?v=QdW6IRsuXaQ.

Boosey, Robyn, and Emily Wilson. 2014. "A Vicious Cycle of Silence: What Are the Implications of the Menstruation Taboo for the Fulfilment of Women and Girls' Human Rights and to What Extent Is the Menstruation Taboo Addressed by International Human Rights Law and Human Rights Bodies?" Sheffield School of Health and Related Research (ScHARR), ScHARR Report Series No. 29.

Bowman, Verity. 2018. "Woman in Nepal Dies after Being Exiled to Outdoor Hut during Her Period." The Guardian, January 12, 2018. https://www. theguardian.com/global-development/2018/jan/12/woman-nepaldies-exiled-outdoor-hut-period-menstruation.

Brooks, Libby. 2018. "Period Poverty: Scotland Poll Shows Women Go to Desperate Lengths." The Guardian, February 5, 2018. https://www.theguardian.com/society $/ 2018 / \mathrm{feb} / 05 /$ period-poverty-scotland-poll-shows-womengo-to-desperate-lengths. 
Dees, J. Gregory. 1998. “The Meaning of Social Entrepreneurship.” Kauffman Foundation and Stanford University. https://centers.fuqua.duke.edu/case/wp-content/uploads/ sites/7/2015/03/Article_Dees_MeaningofSocialEntrepreneurship_2001.pdf.

Dorado, Silvia. 2006. "Social Entrepreneurial Ventures: Different Values so Different Process of Creation, No?" Journal of Developmental Entrepreneurship 11 (4): 31943. https://doi.org/10.1142/s1084946706000453.

Douglas, Lucy. 2017. “'We're Trying to Normalize the Conversation': The UK Firms Rethinking Tampons." The Guardian, November 23, 2017. https://www.theguardian.com/small-business-network/2017/nov/23/ were-trying-to-normalise-the-conversation-the-uk-firms-rethinking-tampons.

Ecofemme. n.d. "EcoFemme • Join the Cloth Pad Revolution!" Accessed April 29, 2020. https://ecofemme.org/.

Emerson, Jed. 2003. "The Blended Value Proposition: Integrating Social and Financial Returns." California Management Review 45 (4): 35-51. https://doi. org/10.2307/41166187.

European Commission. 2015. "Strategic Engagement for Gender Equality 20162019." Accessed March 29, 2018. http://ec.europa.eu/antitrafficking/sites/ antitrafficking/files/strategic_engagement_for_gender_equality_en.pdf.

Freidenfelds, Lara. 2009. The Modern Period: Menstruation in Twentieth-Century America. Baltimore, MD: Johns Hopkins University Press.

George, Amika. 2017. "The Shame of Period Poverty Is Keeping British Girls Out of School: Let's Break the Silence." The Guardian, December 19, 2017. https:// www.theguardian.com/commentisfree/2017/dec/19/british-girls-periodpoverty-menstruation-sanitary-products.

Goggins Gregory, Ann, and Don Howard. 2009. "The Nonprofit Starvation Cycle." Stanford Social Innovation Review 7 (4): 49-53.

Hockerts, Kai. 2006. "Entrepreneurial Opportunity in Social Purpose Business Ventures." In Social Entrepreneurship, edited by J. Mair, J. Robinson, and K. Hockerts, 142-54. Basingstoke: Palgrave Macmillan. https://doi. org/10.1057/9780230625655_10.

House, Sarah, Thérèse Mahon, and Sue Cavill. 2013. "Menstrual Hygiene Matters: A Resource for Improving Menstrual Hygiene Around the World." Reproductive Health Matters 21 (41): 257-59. https://doi.org/10.1016/ s0968-8080(13)41712-3.

Human Rights Watch. 2017. "Understanding Menstrual Hygiene Management \& Human Rights.” Accessed March 29, 2018. https://www.hrw.org/sites/default/ files/news_attachments/mhm_practitioner_guide_web.pdf.

Jackson, Theresa E., and Rachel Joffe Falmagne. 2013. "Women Wearing White: Discourses of Menstruation and the Experience of Menarche." Feminism \& Psychology 23 (3): 379-98. https://doi.org/10.1177/0959353512473812.

Jones, Abigail. 2016. "The Fight to End Period Shaming Is Going Mainstream." Newsweek, April 20, 2016. http://www.newsweek.com/2016/04/29/womens-periods-menstruation-tampons-pads-449833.html.

Joseph, Sinu. 2013. "Menstrual Hygiene Is Not about Sanitary Napkins." Mythri Speaks. Accessed April 25, 2019. https://mythrispeaks.wordpress. com/2013/04/08/menstrual-hygiene-is-not-about-sanitary-napkins-2/.

Karzai, Suraya. 2010. "A Bloody Business: How the Feminine Hygiene Industry Sells Taboos.” The York Scholar 7 (1): 24-32. 
Kissling, Elizabeth Arveda. 1996. "Bleeding Out Loud: Communication about Menstruation.” Feminism \& Psychology 6 (4): 481-504. https://doi. org/10.1177/0959353596064002.

Knix. n.d. "About Us." Accessed April 29, 2020. https://knix.com/pages/about-us.

Kounang, Nadia. 2015. "What's in Your Pad or Tampon?" CNN, November 13, 2015. https://edition.cnn.com/2015/11/13/health/whats-in-your-pad-or-tampon/index.html.

LENA. 2020. "Why LENA.” Accessed April 29, 2020. https://lenacup.com/pages/ what-is-a-menstrual-cup.

Lunette. n.d. "About Us." Accessed April 29, 2020. https://www.lunette.com/ pages/about-us.

Magistretti, Bérénice. 2019. "FemBeat: P\&G Acquires Organic Period Care Startup This Is L." Forbes, February 6, 2019. https://www.forbes.com/sites/berenicemagistretti/2019/02/06/fembeat-pg-acquires-organic-period-care-startupthis-is-1/\#193bdd2e7bb6.

Malefyt, Timothy, and Maryann McCabe. 2016. "Women's Bodies, Menstruation and Marketing 'Protection': Interpreting a Paradox of Gendered Discourses in Consumer Practices and Advertising Campaigns." Consumption Markets \& Culture 19 (6): 555-75. https://doi.org/10.1080/10253866.2015.1095741.

Marsh, Sarah. 2017. "Girls from Poorer Families in England Struggle to Afford Sanitary Protection." The Guardian, March 17, 2017. https:// www.theguardian.com/society/2017/mar/17/girls-from-poorer-familiesin-england-struggle-to-afford-sanitary-protection.

Mcmahon, Shannon A., Peter J. Winch, Bethany A. Caruso, Alfredo F. Obure, Emily A. Ogutu, Imelda A. Ochari, and Richard D. Rheingans. 2011. "The Girl with Her Period Is the One to Hang Her Head Reflections on Menstrual Management among Schoolgirls in Rural Kenya." BMC International Health and Human Rights 11 (1). https://doi.org/10.1186/1472-698x-11-7.

Miller, Jennifer. 2016. "A New Crop of Companies Want to Make Your Period Empowering." Bloomberg, May 18, 2016. https://www.bloomberg.com/news/ articles/2016-05-18/a-new-crop-of-companies-want-to-make-your-period-empowering.

Modibodi. 2020. “Our Story.” Accessed April 29, 2020. https://eu.modibodi.com/ pages/our-story.

Newman, Andrew Adam. 2010. "Rebelling Against the Commonly Evasive Feminine Care Ad." The New York Times, March 15, 2010. https://www.nytimes. com/2010/03/16/business/media/16adco.html.

OrganiCup. n.d. "OrganiCup Menstrual Cup: Easier, Healthier and Greener Periods." Accessed April 29, 2020. https://www.organicup.com/.

Pache, Anne-Claire, and Filipe Santos. 2013. "Inside the Hybrid Organization: Selective Coupling as a Response to Competing Institutional Logics." Academy of Management Journal 56 (4): 972-1001. https://doi.org/10.5465/ amj.2011.0405.

Park, Shelley M. 1996. "From Sanitation to Liberation?: The Modern and Postmodern Marketing of Menstrual Products." The Journal of Popular Culture 30 (2): 149-68. https://doi.org/10.1111/j.0022-3840.1996.00149.x.

PLAN International UK. 2018. "Break the Barriers: Girls' Experiences of Menstruation in the UK." https://plan-uk.org/file/plan-uk-break-the-barriers-report-032018pdf/ download?token $=$ Fs-HYP3v. 
Rabin, Roni Caryn. 2017. "Period Activists Want Tampon Makers to Disclose Ingredients." The New York Times, May 24, 2017. https://www.nytimes. com $/ 2017 / 05 / 24 /$ well/live/period-activists-want-tampon-makers-to-disclose-ingredients.html.

Radnor, Abigail. 2017. "We're Having a Menstrual Liberation': How Periods Got Woke." The Guardian, November 11, 2017. https://www.theguardian.com/society/2017/nov/11/periods-menstruation-liberation-women-activists-abigail-radnor.

Ratcliff, Rebecca. 2017. "Tampons That Care: Helping Girls Across the World to End 'Shame of Periods'." The Guardian, May 28, 2017. https://www.theguardian.com/global-development/2017/may/27/ one-for-one-firms-target-stigma-menstruation.

Ruby Cup. 2020. “How we Give.” Accessed April 29, 2020. https://rubycup.com/ pages/how-we-give.

Schechtman, Lisa. 2015. "Why Tackling the Stigma Around Menstruation Is Key to Gender Equality." World Economic Forum, May 29, 2015. https:// www.weforum.org/agenda/2015/05/why-tackling-the-stigma-aroundmenstruation-is-key-to-gender-equality/.

Siebert, Valerie. 2018. "Nearly Half of Women have Experienced 'Period Shaming.'” New York Post, January 3, 2018. https://nypost.com/2018/01/03/ nearly-half-of-women-have-experienced-period-shaming.

Sommer, Marni, Jennifer S. Hirsh, Constance Nathanson, Richard G. Parker. 2015. "Comfortably, Safely, and Without Shame: Defining Menstrual Hygiene Management as a Public Health Issue." American Journal of Public Health 105 (7): 1302-11. https://doi.org/10.2105/ajph.2014.302525.

Thomas, Erika. 2007. "Menstruation Discrimination: The Menstrual Taboo as a Rhetorical Function of Discourse in the National and International Advances of Women's Rights." Contemporary Argumentation and Debate 28: 65-90.

Tracey, Paul, Nelson Phillips, and Owen Jarvis. 2011. "Bridging Institutional Entrepreneurship and the Creation of New Organizational Forms: A Multilevel Model." Organization Science 22 (1): 60-80. https://doi.org/10.1287/ orsc. 1090.0522 .

United Nations. 2015. "Transforming Our World: The 2030 Agenda for Sustainable Development." Accessed March 29, 2018. https://sustainabledevelopment. un.org/post2015/transformingourworld.

Vostral, Sharra Louise. 2008. Under Wraps: A History of Menstrual Hygiene Technology. Lanham, MD: Lexington Books.

Weiss-Wolf, Jennifer. 2019. Periods Gone Public: Taking a Stand for Menstrual Equity. New York: Arcade Publishing.

World Health Organization. 2015. “Global Strategy for Women's, Children's and Adolescents' Health 2016-2030.” Accessed March 29, 2018. http://www.who. int/life-course/publications/global-strategy-2016-2030/en/.

Wydick, Bruce, Elizabeth Katz, and Brendan Janet. 2014. "Do In-Kind Transfers Damage Local Markets? The Case of TOMS Shoe Donations in El Salvador." Journal of Development Effectiveness 6 (3): 249-267. http://dx.doi.org/10.1080/ 19439342.2014.919012.

Ziv, Stav. 2017. "Periods Are Normal, Says First U.K. Commercial to Use Red Liquid on a Pad." Newsweek, October 19, 2017. http://www.newsweek.com/ periods-are-normal-says-first-uk-commercial-use-red-liquid-pad-688699. 
Open Access This chapter is licensed under the terms of the Creative Commons Attribution 4.0 International License (http://creativecommons.org/licenses/ by/4.0/), which permits use, sharing, adaptation, distribution and reproduction in any medium or format, as long as you give appropriate credit to the original author(s) and the source, provide a link to the Creative Commons license and indicate if changes were made.

The images or other third party material in this chapter are included in the chapter's Creative Commons license, unless indicated otherwise in a credit line to the material. If material is not included in the chapter's Creative Commons license and your intended use is not permitted by statutory regulation or exceeds the permitted use, you will need to obtain permission directly from the copyright holder. 